\title{
Correction to: Ora-pro-nobis (Pereskia aculeata Mill.) Nutrition as Related to Soil Chemical and Physical Attributes and Plant Growth-Promoting Microorganisms
}

César Florentino Puma Vega ${ }^{1}$ - Karl Kemmelmeier ${ }^{1}$. Márcia Rufini ${ }^{1} \cdot$ Teotonio Soares de Carvalho $^{1}$. Fatima Maria de Souza Moreira ${ }^{1}$

Published online: 28 May 2020

(C) Sociedad Chilena de la Ciencia del Suelo 2020

Correction to: Journal of Soil Science and Plant Nutrition https://doi.org/10.1007/s42729-020-00235-9

An incorrect graphic is presented for Fig. 4 in this article. The correct graphic for Fig. 4 is given below.

The online version of the original article can be found at https://doi.org/ $10.1007 / \mathrm{s} 42729-020-00235-9$

Fatima Maria de Souza Moreira fmoreira@ufla.br

1 Setor de Biologia, Microbiologia e processos biológicos do solo, Departamento de Ciência do Solo, Universidade Federal de Lavras, Lavras CEP 37200-000, Brazil 
Fig. 4 Distribution of the genera of bacteria isolated from different types of samples from ora-pronobis (Pereskia aculeata Mill.) from twelve locations in the south of MG, Brazil. The genus that occurred in all types of samples is in the intercession. The number of individuals isolated from each genus in each type of sample is described in parentheses

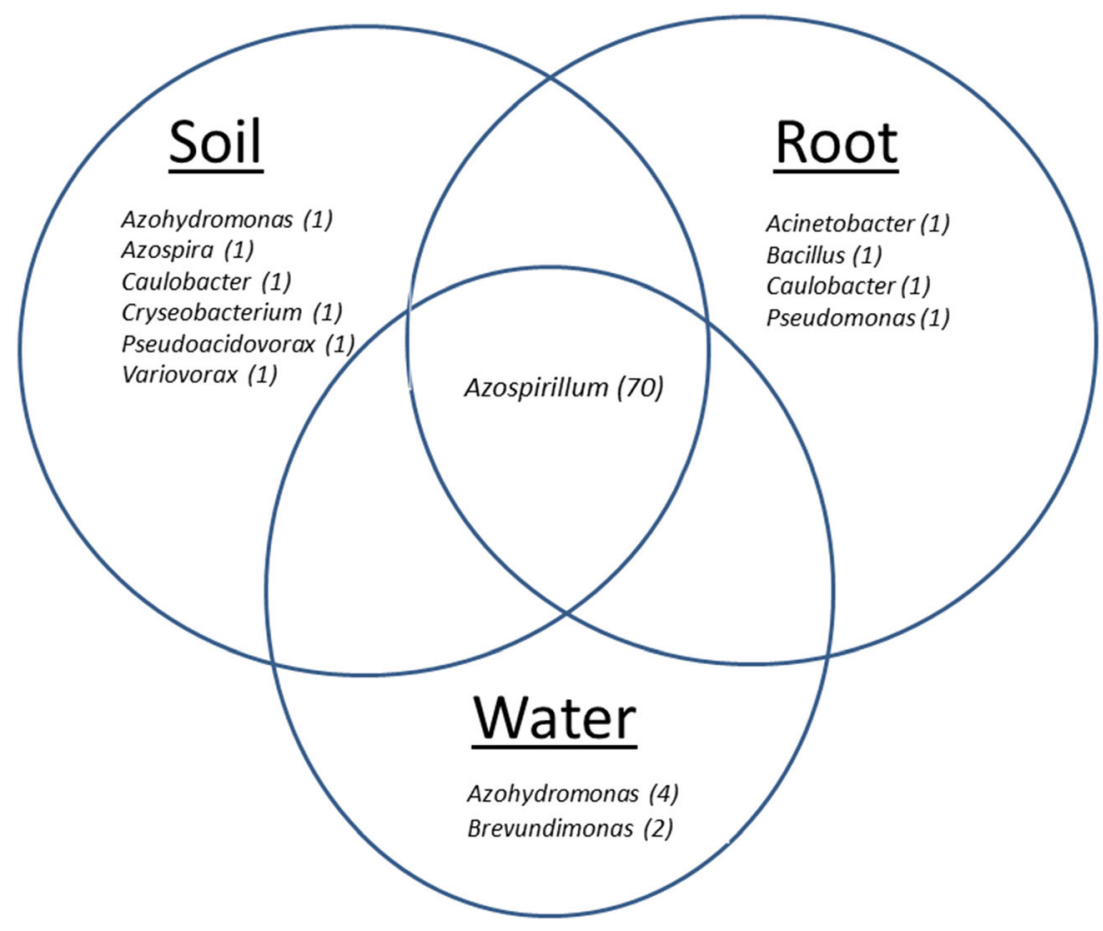

